\section{HOLOCAIN VS. COCAIN.}

\author{
BY F. C. HOTZ, M.D. \\ GHICAGO.
}

Early in August I received from the druggists Gale \& Blocki, a 1 per cent. solution of holocain for testing its anesthetizing virtues. I first tried it on a few normal eyes and on eyes with foreign bodies in the cornea, with the following results: The instillation always caused more or less smarting and burning, which however lasted but about half a minute; it also produced considerable redness of the conjunctiva (palpebral and ocular), which persisted during the whole period of anesthesia. Within one and onehalf to two minutes complete anesthesia of the cornea was noted; after six minutes the sensibility of the cornea began to return, but a second instillation prolonged the anesthesia for another five minutes; and if tnen another drop was instilled the anesthesia could again be continued. It would seem then that the anesthetic effect of holocain can be kept up indefinitely by repeating the instillation every five minutes. With cocain this can not be done; at least I have noticed that if the eye is coming out of the cocain anesthesia, repeated instillations do not restore the anesthesia; on the contrary, I have often found the eye becoming more sensitive the more cocain was used. Holocain does not contract the conjunctival blood vessels and therefore causes neither bleaching of the eye nor lessening of the lacrymal secretion nor drying of the corneal epithelium. It does not dilate the pupil and has no effect on the accommodation. On account of these qualities one would naturally feel inclined to use this new anesthetic in preference of cocain, in all operations on the eye. But a series of comparative tests of the efficiency of the two remedies seemed to show that the anesthetizing effect of cocain ( 2 per cent.) is more thorough and penetrating than that of holocain ( 1 per cent.). I had, for instance, two patients with corneal ulcers which required the repeated application of the electro-cautery. I made one application under holocain anesthesia and the next time cauterized the same eye under cocain. Both patients, who thought cocain was used on both occasions, said the first cauterization was decidedly painful, while they did not feel the second one at all. I performed an advancement of the externus on the right eye under holocain and on the left eye of the same patient under cocain; complete anesthesia of the conjunctiva in both eyes; but the cutting and suturing of the tendon was decidedly painful in the holocainized eye, while scarcely felt in the cocainized eye.

The most telling illustration of the difference in their penetrating effect was furnished by a case of subconjunctival injections of cyanid of mercury. Several injections had previously been made under cocain and the pain following the injections was moderate and never lasted over five to ten minutes. The next injection was made under holocain and caused the most violent pain, which after twenty minutes showed no sign of letting upin intensity; I then instilled cocain and within five minutes the patient was free from pain. One week later this experiment was repeated with the same result.

All these observations seem to show that the effect of holocain is very quick, but superficial; it is therefore a very useful local anesthetic for the removal of foreign bodies from the cornea, and for operations upon the conjunctiva; but for deeper operations, and especially for those which involve the opening of the globe (iridectomy and cataract extraction), I regard cocain as the more reliable anesthetic.

\section{SURGERY ONE HUNDRED YEARS AGO.}

AN HISTORICAL STUDY

BY DR. GEORGE FISCHER.

DEDICATED TO THE GERMAN SURGICAL ASgOCIATION.

TRANGLATED FOR THE JOURNAL OF THE AMRRICAN MEDICAL ASSOCIATION BY CARL H. VON KLEIN, A.M., M.D.

XVI.-DISEASES OF THE BLOOD VESSELS, NERVES AND SKIN. NEOPLASMS.

(Continued from page 965.)

Tetamus was not unknown to the German military physicians. Bilguer relates that after the battle of Prague (17j̃), several thousands with slight wounds died in the field hospitals of so-called "dog-cramp," in spite of careful treatment by Cothenius, Schmucker and others; and the same was true after the battle of Liegnitz. Later in the war he saw the cramp more rarely. The bad hospital air was recognized as the cause of tetanus (in which A. de Haën had already measured the higher temperatures) and Theden recommended ventilation for the improvement of the air, as a prophylactic remedy for tetanus, although a draft often induced it. Certain ligatures were also condemned as a cause of tetanus, especially in castration (Theden, Plenk and Morand). Bilguer attached great importance to local treatment, and enlarged gunshot wounds in length and depth in order to bring about widening. Plenk and Siebold amputated with success, for which method Larrey in particular later entered the lists. In internal treatment opium, especially recommended by Petit and Bilguer, stood in high repute, and large doses were given without hesitation; Windsor gave 25 drops of laudanum every three hours. Charles White gave 317 grains of poppy juice within five weeks with success. Others, on the contrary, saw no use whatever in opium, and since it was said principally to effect relaxation, they preferred quinia and wine (Rush). Charles White advocated warm baths; cold water, which the ancients applied, was endorsed by Wright in Jamaica, who poured a fow pailfuls over the patients every few hours, and also by Curne, who threw his patients into water and immersed them several times. J. Hunter declared in his lectures that he would proceed with the disease according to Zamblé and have himself put into an ice-house.

Parry of Bath first introduced therapeutically the compression of the carotid for certain nervous diseases (1789). Rufus of Ephesus and Columbus knew this method. Parry would in this way relieve delirium, dizziness and convulsions, but noticed a return of the symptoms as soon as the pressure ceased. Severe headache, for which Felix Würtz had one of the art. temporales severed, and had "given praise, honor and thanks to God Almighty" for the cessation of the pain, Parry had relieved immediately by compression of the carotid or the temporal. He allayed pain in the feet by compression of the art. poplitea, pain from panaritium by a pressure upon both sides of the fingers. Compression of the carotid was also recommended for facial pains. When Fothergill first accurately described this ill (1776), already known to the ancients, to which the Versailles surgeon André gave the name tic douloureux. (1753), he regarded 